\title{
PHYSICAL ACTIVITY OF FUTURE HEALTH CARE PROFESSIONALS: ADHERENCE TO CURRENT RECOMMENDATIONS
}

\author{
Anna Lipert ${ }^{1}$, Ewelina Matusiak-Wieczorek ${ }^{1}$, Ewa Kochan², Piotr Szymczyk², Magdalena Wrzesińska ${ }^{3}$, Anna Jegier ${ }^{1}$ \\ Medical University of Lodz, Łódź, Poland \\ ${ }^{1}$ Department of Sports Medicine \\ ${ }^{2}$ Pharmaceutical Biotechnology Department \\ ${ }^{3}$ Department of Psychosocial Rehabilitation
}

\begin{abstract}
Objectives: When assessing physical activity (PA), particular attention should be paid to medical university students who are taught to be health care professionals (HCPs) responsible for maintaining health in humans. However, different studies have shown that HCPs exhibit the same unhealthy behaviors as the general population. This study analyzed PA among medical university students of different faculties and their adherence to current PA recommendations. Material and Methods: Data from 216 medical university students of physiotherapy, dietetics and pharmacy, including males $(\mathrm{N}=44)$ and females $(\mathrm{N}=172)$, the mean age of $22.3 \pm 1.8$ years, were collected. The International Physical Activity Questionnaire in its long form (IPAQ-LF) was used to assess and classify PA behaviors. The results were analyzed in accordance with World Health Organization recommendations regarding PA. Results: Over $60 \%$ of all the students were classified as active during all-day activity. However, while analyzing PA in different domains, the same shares of all the students were still insufficiently active during leisure time, and so they did not meet the recommendation of $>75 \mathrm{~min} /$ week of vigorous PA, $>150 \mathrm{~min} /$ week of moderate PA or an equivalent combination. All the students self-reported PA mainly in the work and transport domains. Generally, physiotherapy students were the most active and performed PA with higher intensity. Conclusions: This study revealed a low level of leisure time PA among the students, and no habit of regular PA. Some changes in medical education should be suggested to include physical education as a long-term subject in medical school curricula. Future research is needed to investigate the exercise barriers that students perceive, which can guide future interventions aimed at improving their PA, and thereby impact on the quality of health care which they will provide. Med Pr. 2020;71(5):539-49
\end{abstract}

Key words: physical activity level, students, self-report, health promotion, health care professionals, guidelines

Corresponding author: Anna Lipert, Medical University of Lodz, Department of Sports Medicine, Pomorska 251, 92-213 Łódź, Poland, e-mail: anna.lipert@umed.lodz.pl

Received: January 8, 2020, accepted: May 6, 2020

\section{INTRODUCTION}

Medical university students are taught to be health care professionals (HCPs) whose role is to maintain health in humans by applying the principles and procedures of evidence-based medicine. Healthy People 2020, the national health objectives established by the U.S. Department of Health and Human Services, emphasized the importance of HCPs discussing health behaviors with patients [1]. In particular, promoting physical activity (PA) is essential in the face of the constantly rising health care costs, obesity rates, and other public health threats resulting from the lack of PA [2].

A HCP is a student graduating from different courses of health care studies, including allied HCPs like dietitians, physiotherapists or pharmacists. Pharmacists are HCPs who have a special relationship with many of their regular customers, which enables them to promote health [3]. Undergraduate physiotherapy students represent a group of young adults who are expected to promote and prescribe exercises to patients and the general public, so they have a great potential for promoting PA [4]. Dietitians are regulated HCPs licensed to assess, diagnose and treat nutritional problems, but also educate clients about the connection between food, fitness and health [5].

It is very important that HCPs provide adequate counseling to their patients in order for the number of regularly active adults to increase [6]. It has been shown among medical students that the personal PA levels are correlated with the frequency of PA counseling to their patients [7]. Moreover, physicians and medical students with a normal body mass index (BMI), who practice moderate PA (MPA) and/or vigorous PA (VPA), are more likely to feel confident about counseling their patients about PA than their colleagues who do not prac- 
tice PA or are overweight [8]. Finally, people planning to be HCPs should be under pressure to fit a certain image that is congruent with their future profession if they want to seem more reliable to the patient. Therefore, it would be desirable for medical university students to perform an adequate level of PA during college years, which would likely influence the habitual PA during their adult life [9].

Current literature describes studies on PA levels of young adults across all age groups and education levels $[10,11]$, including medical university students [12]. However, the research most often concerns students of medicine, while studies analyzing the PA of students in different fields of health sciences, the so-called paramedical studies, are sparse [13]. At the same time, studies assessing PA and the prevalence of compliance with PA guidelines in a sub-population of medical students confirmed the need to develop interventions to improve and support active lifestyle behaviors among university students $[7,8]$. Therefore, the research was carried out to assess the level of PA among the students of pharmacy $(\mathrm{Ph})$, dietetics $(\mathrm{D})$ and physiotherapy $(\mathrm{P})$, and their compliance with current recommendations to increase the students' awareness of PA and its importance in relation to both their patients and themselves.

\section{MATERIAL AND METHODS}

A cross-sectional survey was conducted among 274 medical university students currently pursuing physiotherapy, dietetics or pharmacy studies. Finally, the study involved 216 students (a response rate $=78.8 \%$ ) of the reference faculties, including males $(\mathrm{N}=44)$ and females $(\mathrm{N}=172)$, aged $22.3 \pm 1.8$ years, who returned fully completed questionnaires. The subjects were invited to participate in the study via advertisement. The data was collected during the academic year, in October 2016-June 2017. The surveys were completed independently by the students. The interviewees were explained what the purpose of the survey was and how to complete the procedure. Participation in the study was voluntary and did not involve any form of gratification. Completing the questionnaire was anonymous and equivalent to agreeing to participate in the study, so the relevant University Human Ethics Committee decided to exempt it from its approval. The study meets the ethical standards of the journal.

The PA level was self-reported using the International Physical Activity Questionnaire in its long form (IPAQ-LF) which estimates the weekly PA (the last
7 days' activity) across different domains [14,15]. Each domain assessed walking PA (WPA), MPA and VPA performed for $\geq 10$ consecutive min/day, over 7 days. The final results of IPAQ, presented as a metabolic equivalent [MET-min/week], were processed in accordance with the IPAQ scoring protocol guideline $[14,16]$, and analyzed according to the World Health Organization (WHO) recommendations for adults aged 18-64 years [17]. Regarding the adherence to the WHO recommendations, the participants were classified into 3 PA categories [18]: "inactive" if they participated in $<150 \mathrm{~min} /$ week of MPA, or $<75 \mathrm{~min} /$ week of VPA, or an equivalent combination of the 2 intensities; "sufficiently active" if they had 150-299 min/week of MPA, or 75-149 min/week of VPA, or an equivalent combination; or "very active" if they participated in $\geq 300 \mathrm{~min} /$ week of MPA, or $\geq 150 \mathrm{~min} /$ week of VPA, or an equivalent combination, considering bouts of $\geq 10 \mathrm{~min}$. The participants were classified as very active if they accumulated at least twice the minimum WHO recommendation.

The analyses were performed in July 2017. The differences between the levels of PA in the study groups according to gender, age and faculty were verified by Mann-Whitney U test. Multivariate logistic regression was used to evaluate the association between the level or intensity of performed PA, on the one hand, and gender and faculty, on the other. All confidence intervals (CIs) are presented as $95 \%$ CIs.

The reliability of IPAQ-LF used in the study group was evaluated by determining internal consistency. The internal consistency (Cronbach's a coefficient) for IPAQ was 0.62 , which indicated moderately acceptable reliability and internal consistency. The subscales of IPAQ Cronbach's a coefficient of reliability were observed to vary between $0.57-0.62$.

All the analyses were carried out using Statistica (StatSoft Inc., version 10) and p $<0.05$ was considered as statistically significant.

\section{RESULTS}

\section{Characteristics of the study group and PA levels}

The general characteristic of the study group, together with PA levels, are shown in Table 1. The PA level of the male participants was significantly higher than that of the female participants $(\mathrm{p}<0.05)$ regardless of the faculty and PA intensity (Table 1, Figure 1).

The male $\mathrm{P}$ students self-reported much more VPA and MPA than the female P students, while the male D 
Table 1. Characteristics of the physical activity (PA) level of the medical university students analyzed during the academic year, in October 2016-June $2017(\mathrm{~N}=216)$, by gender and faculty

\begin{tabular}{|c|c|c|c|}
\hline Variable & \multicolumn{3}{|c|}{$\begin{array}{c}\text { Participants } \\
(\mathrm{N}=216) \\
(\mathrm{M} \pm \mathrm{SD})\end{array}$} \\
\hline Age [years] & $22.3 \pm 1.8$ & $22.9 \pm 3.5$ & $22.2 \pm 0.9^{\mathrm{a}}$ \\
\hline pharmacy students $(\mathrm{N}=73)$ & $22.0 \pm 0.8$ & $22.4 \pm 0.7$ & $22.0 \pm 0.8$ \\
\hline Total PA [MET-min/week] & $6266.3 \pm 6925.5$ & $10691.1 \pm 12152.8$ & $5134.4 \pm 4103.5^{\mathrm{a}}$ \\
\hline physiotherapy students & $8095.4 \pm 8806.9$ & $12125.0 \pm 13977.2$ & $6472.3 \pm 4784.8^{\mathrm{a}}$ \\
\hline physiotherapy students & $2377.8 \pm 3905.1$ & $5030.3 \pm 5817.5$ & $1309.4 \pm 2024.9^{\mathrm{a}}$ \\
\hline dietetics students & $1266.7 \pm 1965.2$ & $3053.3 \pm 2046.8$ & $968.9 \pm 1813.0^{\mathrm{a}}$ \\
\hline pharmacy students & $748.2 \pm 1252.9^{c}$ & $1217.8 \pm 2008.3$ & $682.1 \pm 1116.2^{c}$ \\
\hline MPA [MET-min/week] & $1753.0 \pm 2379.1$ & $2679.0 \pm 4076.3$ & $1516.1 \pm 1631.4^{\mathrm{a}}$ \\
\hline physiotherapy students & $2341.4 \pm 3010.6$ & $3291.7 \pm 4686.3$ & $1958.7 \pm 1894.1^{\mathrm{a}}$ \\
\hline dietetics students & $1178.2 \pm 1243.5^{b}$ & $745.8 \pm 786.7$ & $1250.2 \pm 1298.3^{b}$ \\
\hline pharmacy students & $1269.7 \pm 1586.7^{c}$ & $1993.3 \pm 2714.0$ & $1167.9 \pm 1362.6^{c}$ \\
\hline Walking [MET-min/week] & $2902.3 \pm 3415.8$ & $4031.3 \pm 5411.3$ & $2613.5 \pm 2625.8^{a}$ \\
\hline dietetics students & $2215.7 \pm 1230.1^{\mathrm{b}}$ & $3000.0 \pm 1548.4$ & $2085.0 \pm 1143.2^{\mathrm{b}}$ \\
\hline pharmacy students & $3086.0 \pm 1032.1^{\mathrm{d}}$ & $2594.4 \pm 1042.6$ & $3155.2 \pm 1019.8^{\mathrm{d}}$ \\
\hline Average sitting [h/day] & $6.6 \pm 2.9$ & $6.1 \pm 2.8$ & $6.8 \pm 3.0$ \\
\hline physiotherapy students & $6.7 \pm 3.1$ & $5.8 \pm 2.7$ & $7.0 \pm 3.2$ \\
\hline dietetics students & $5.3 \pm 2.9^{\mathrm{b}}$ & $7.1 \pm 3.7$ & $5.0 \pm 2.7^{\mathrm{b}}$ \\
\hline pharmacy students & $7.3 \pm 2.5^{\mathrm{d}}$ & $6.2 \pm 2.5$ & $7.5 \pm 2.4^{\mathrm{d}}$ \\
\hline
\end{tabular}

${ }^{a}$ Vs. males.

${ }^{\mathrm{b}}$ Physiotherapy vs. dietetics.

${ }^{c}$ Physiotherapy vs. pharmacy.

${ }^{\mathrm{d}}$ Dietetics vs. pharmacy.

MET - metabolic energy turnover (metabolic equivalent), MPA - moderate physical activity, VPA - vigorous physical activity.

Significant differences among different points inside the groups $(\mathrm{p}<0.05)$.

students self-reported much more MPA or WPA than the female D students (Table 1, Figure 1). Generally, the level of total PA expressed in MET in the P students was the highest as compared the students of the oth- er 2 faculties, and it was statistically significant (Table 1). The female $P$ students were also more active than the other female students (Table 1). As regards PA intensity, the female P students self-reported much more MPA 
a)

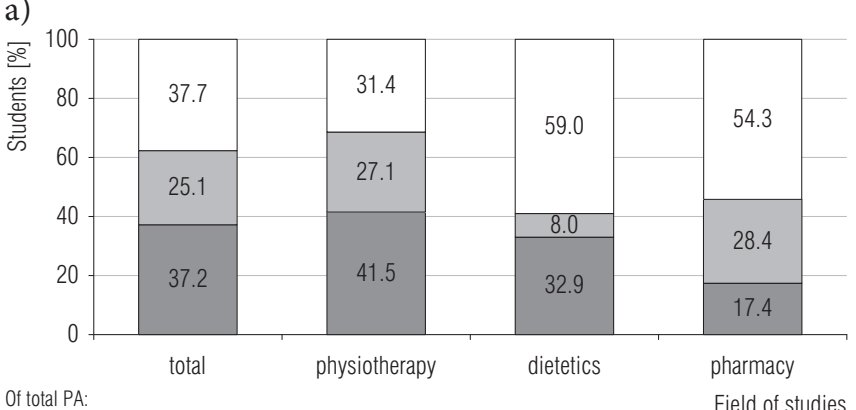

Of total PA:

$\square$ VPA $\square$ MPA $\square$ WPA

b)

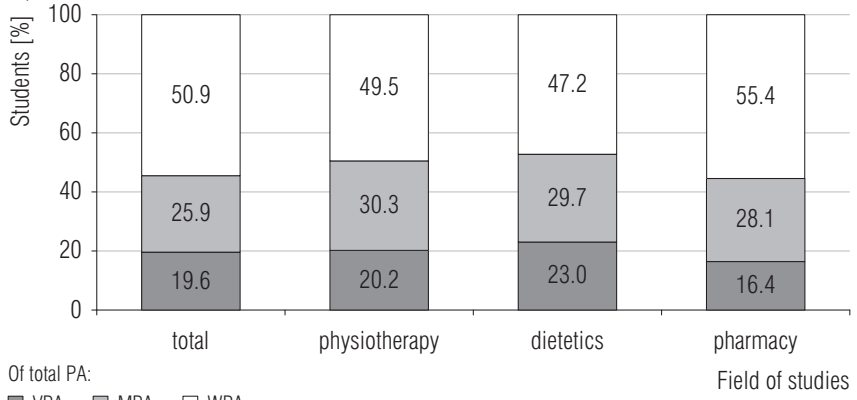

$\square$ VPA $\square$ MPA $\square$ WPA

c)

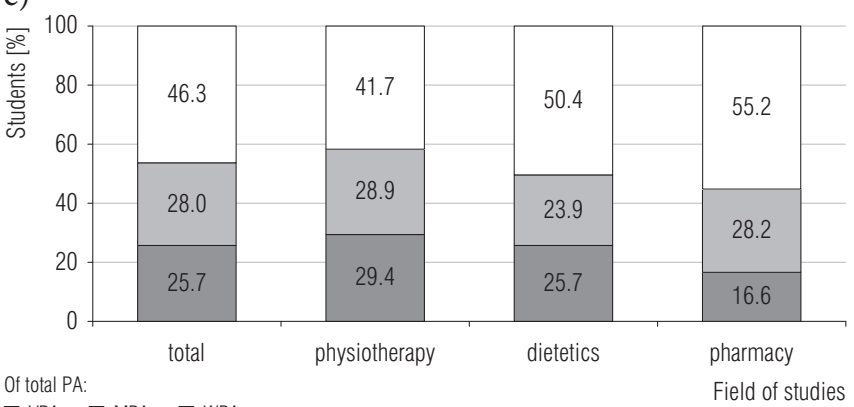

$\square$ VPA $\square$ MPA $\square$ WPA

MPA - moderate physical activity, VPA - vigorous physical activity, WPA - walking physical activity.

Figure 1. Physical activity (PA) of varying intensity performed by the medical university students analyzed during the academic year, in October 2016-June 2017, by field of studies: in a) the whole study group, b) male students, c) female students

and WPA than the female D students, and much more VPA and MPA than the female Ph students (Table 1).

\section{Level of PA and its areas} according to IPAQ scoring

According to the IPAQ categorical score, $1.4 \%$ of all the students were inactive, while $64.8 \%$ were in the very active group (Table 2). There were no inactive subjects among the D students, while the Ph students were those who constituted the most numerous group of very active subjects (Table 2).

There were statistically significant differences in the PA levels in the male and female students. Fewer a)

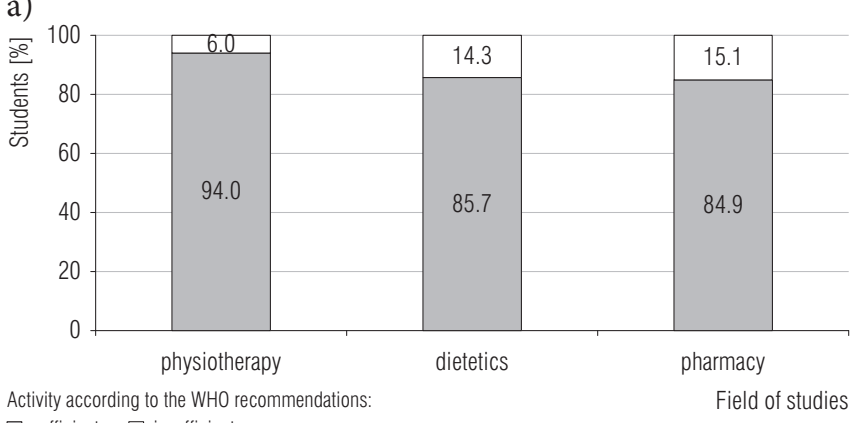

$\square$ sufficient $\quad \square$ insufficient

b)

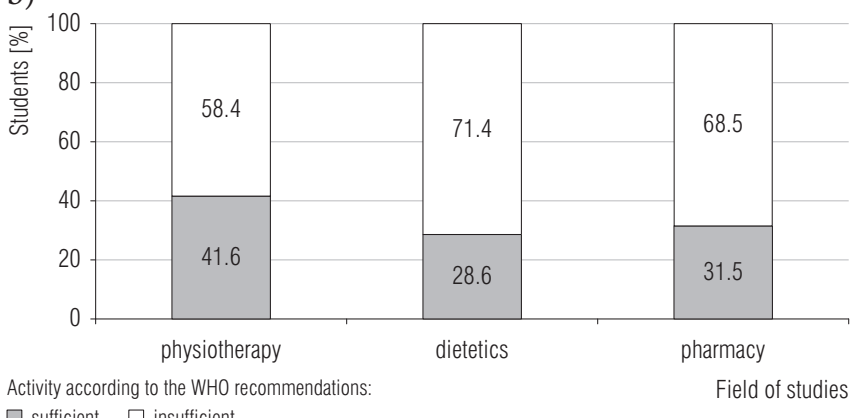

$\square$ sufficient $\square$ insufficient

Figure 2. Medical university students analyzed during the academic year, in October 2016-June 2017, meeting the PA recommendations (according to $\mathrm{WHO}$ ): a) overall $\mathrm{PA}, \mathrm{b}$ ) leisure time PA

female students were scored as very active, compared to the male students ( $\mathrm{OR}=4.35,95 \% \mathrm{CI}: 1.74-10.83$, $\mathrm{p}=0.002)$, but more female students were scored as sufficiently active (OR $=0.25,95 \%$ CI: $0.10-0.62$, $\mathrm{p}=0.003)($ Table 3$)$.

As regards specific domains, physical inactivity was higher for the household domain compared to other domains, with most of the students being relatively active in the transport domain regardless of the field of studies (Table 2). Generally, the male students were much more physically active at work than the female students, and the most pronounced statistically significant difference was seen between the males and females who were scored as very active (OR $=4.14,95 \%$ CI: $2.06-8.30$, $\mathrm{p}=0.0001$ ) (Table 2). Moreover, more male students than female students self-reported leisure time PA, and the former were scored significantly more often as very active $(\mathrm{OR}=5.68,95 \% \mathrm{CI}: 2.70-11.95, \mathrm{p}=0.001)$ (Table 3).

There were statistically significant differences in various domains between the students with respect to the field of studies. Fewer P students were inactive in all the domains as compared to the $\mathrm{D}$ and $\mathrm{Ph}$ students (Tables 2 and 3). Moreover, the P students were more frequently scored as very active in all the domains (Tables 2 and 3 ). 
Table 2. Domain-specific physical activity (PA) levels of the medical university students analyzed during the academic year, in October 2016-June 2017, by IPAQ scoring

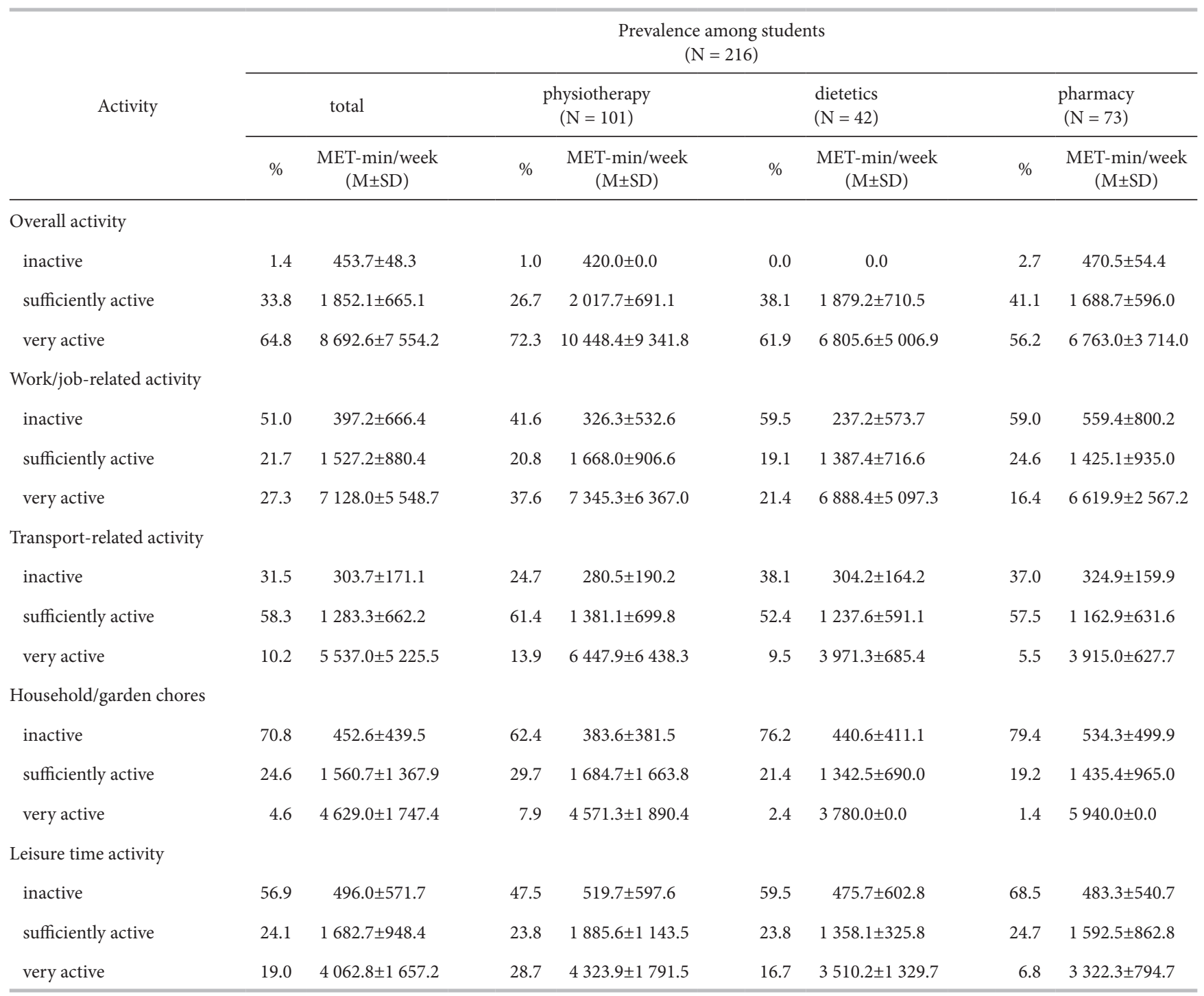

IPAQ - International Physical Activity Questionnaire, MET - metabolic energy turnover (metabolic equivalent).

\section{Students' PA in relation \\ to the WHO recommendations}

In the whole group, $10.6 \%$ of the students were inactive, which means that they did not meet the recommendation of almost $75 \mathrm{~min} /$ week of VPA, or almost $150 \mathrm{~min} /$ week of MPA, or an equivalent combination (neither $<150 \mathrm{~min} /$ week of MPA nor $<75 \mathrm{~min} /$ week of VPA) (Table 3). The P students were the most physically active group, because only $5.9 \%$ of them were scored as inactive. The shares of the $\mathrm{D}$ and $\mathrm{Ph}$ students who were scored as inactive were quite similar (14.3\% and $15.1 \%$, respectively) (Figure 2, Table 4).

When analyzing the PA recommendations in different domains, it was found that the students of all the fac- ulties were the least active in the household domain and the most active in work domain. In the work domain, $33.7 \%$ of the P students were scored as very active, which means that they participated in $\geq 300 \mathrm{~min} /$ week of MPA, or $\geq 150 \mathrm{~min} /$ week of VPA, or an equivalent combination. The $\mathrm{D}$ and $\mathrm{Ph}$ students were more often scored as sufficiently active, so they had 150-299 $\mathrm{min} /$ week of MPA, or 75-149 min/week of VPA, or an equivalent combination. In the household domain, the D students were the least physically active group (Table 4 ).

When analyzing the recommendations of leisure time PA, it was found that $64.4 \%$ of all the students were inactive, and the $\mathrm{D}$ students were the least physically active group (Figure 2, Table 4). 
Table 3. Multivariate logistic regression of the physical activity (PA) levels of the medical university students analyzed during the academic year, in October 2016-June 2017 ( $\mathrm{N}=216)$, by gender and faculty

\begin{tabular}{|c|c|c|c|c|c|c|c|c|c|}
\hline \multirow{3}{*}{ Variable } & \multicolumn{9}{|c|}{ PA level } \\
\hline & \multicolumn{3}{|c|}{ inactive } & \multicolumn{3}{|c|}{ sufficiently active } & \multicolumn{3}{|c|}{ very active } \\
\hline & OR & $95 \% \mathrm{CI}$ & $\mathrm{p}$ & OR & $95 \% \mathrm{CI}$ & $\mathrm{p}$ & OR & $95 \% \mathrm{CI}$ & $\mathrm{p}$ \\
\hline \multicolumn{10}{|l|}{ Overall activity } \\
\hline \multicolumn{10}{|l|}{ gender } \\
\hline male & 0.54 & $0.03-10.73$ & 0.689 & 0.25 & $0.10-0.62$ & 0.003 & 4.35 & $1.74-10.83$ & 0.002 \\
\hline female & 1.00 & & & 1.00 & & & 1.00 & & \\
\hline \multicolumn{10}{|l|}{ faculty } \\
\hline physiotherapy students & 0.35 & $0.03-3.99$ & 0.401 & 0.52 & $0.27-0.99$ & 0.048 & 2.03 & $1.08-3.84$ & 0.028 \\
\hline dietetics student & 0.34 & $0.02-7.18$ & 0.485 & 0.88 & $0.40-1.92$ & 0.752 & 1.27 & $0.58-2.75$ & 0.548 \\
\hline pharmacy students & 1.00 & & & 1.00 & & & 1.00 & & \\
\hline \multicolumn{10}{|l|}{ Work/job-related activity } \\
\hline \multicolumn{10}{|l|}{ gender } \\
\hline male & 0.32 & $0.16-0.66$ & 0.002 & 2.36 & $1.17-4.75$ & 0.016 & 4.14 & $2.06-8.30$ & 0.0001 \\
\hline female & 1.00 & & & 1.00 & & & 1.00 & & \\
\hline \multicolumn{10}{|l|}{ faculty } \\
\hline physiotherapy students & 0.50 & $0.27-0.91$ & 0.025 & 0.80 & $0.39-1.64$ & 0.547 & 3.07 & $1.46-6.41$ & 0.003 \\
\hline dietetics students & 1.03 & $0.47-2.22$ & 0.948 & 0.72 & $0.28-1.83$ & 0.490 & 1.39 & $0.53-3.63$ & 0.506 \\
\hline pharmacy students & 1.00 & & & 1.00 & & & 1.00 & & \\
\hline \multicolumn{10}{|l|}{ Transport-related activity } \\
\hline \multicolumn{10}{|l|}{ gender } \\
\hline male & 0.41 & $0.18-0.95$ & 0.037 & 1.70 & $0.84-3.42$ & 0.140 & 1.54 & $0.56-4.20$ & 0.399 \\
\hline female & 1.00 & & & 1.00 & & & 1.00 & & \\
\hline \multicolumn{10}{|l|}{ faculty } \\
\hline physiotherapy students & 0.56 & $0.29-1.08$ & 0.083 & 1.17 & $0.63-2.17$ & 0.609 & 2.77 & $0.87-8.81$ & 0.083 \\
\hline dietetics students & 1.05 & $0.48-2.29$ & 0.906 & 0.81 & $0.38-1.74$ & 0.592 & 1.81 & $0.43-7.67$ & 0.417 \\
\hline pharmacy students & 1.00 & & & 1.00 & & & 1.00 & & \\
\hline \multicolumn{10}{|l|}{ Household/garden chores } \\
\hline \multicolumn{10}{|l|}{ gender } \\
\hline male & 1.12 & $0.54-2.35$ & 0.757 & 0.88 & $0.40-1.93$ & 0.755 & 0.98 & $0.20-4.77$ & 0.976 \\
\hline female & 1.00 & & & 1.00 & & & 1.00 & & \\
\hline \multicolumn{10}{|l|}{ faculty } \\
\hline physiotherapy students & 0.43 & $0.21-0.86$ & 0.017 & 1.78 & $0.86-3.67$ & 0.117 & 6.19 & $0.76-50.65$ & 0.089 \\
\hline dietetics students & 0.83 & $0.33-2.05$ & 0.683 & 1.15 & $0.45-2.94$ & 0.771 & 1.76 & $0.11-28.83$ & 0.693 \\
\hline pharmacy students & 1.00 & & & 1.00 & & & 1.00 & & \\
\hline \multicolumn{10}{|l|}{ Leisure time activity } \\
\hline \multicolumn{10}{|l|}{ gender } \\
\hline male & 0.31 & $0.16-0.63$ & 0.001 & 0.77 & $0.34-1.73$ & 0.530 & 5.68 & $2.70-11.95$ & 0.0001 \\
\hline female & 1.00 & & & 1.00 & & & 1.00 & & \\
\hline
\end{tabular}


Table 3. Multivariate logistic regression of the physical activity (PA) levels of the medical university students analyzed during the academic year, in October 2016-June $2017(\mathrm{~N}=216)$, by gender and faculty - cont.

\begin{tabular}{|c|c|c|c|c|c|c|c|c|c|}
\hline \multirow{2}{*}{ Variable } & \multicolumn{9}{|c|}{ PA level } \\
\hline & OR & $95 \%$ CI & $\mathrm{p}$ & OR & $95 \%$ CI & $\mathrm{p}$ & OR & $95 \%$ CI & $\mathrm{p}$ \\
\hline \multicolumn{10}{|l|}{ Leisure time activity - cont. } \\
\hline \multicolumn{10}{|l|}{ faculty } \\
\hline dietetics students & 0.68 & $0.31-1.50$ & 0.332 & 0.95 & $0.39-2.32$ & 0.919 & 2.72 & $0.80-9.19$ & 0.107 \\
\hline pharmacy student & 1.00 & & & 1.00 & & & 1.00 & & \\
\hline
\end{tabular}

Significant differences between different points inside the groups $(\mathrm{p}<0.05)$.

Bolded are statistically significant differences $(\mathrm{p}<0.05)$.

Table 4. Domain-specific physical activity (PA) levels of the medical university students analyzed during the academic year, in October 2016-June 2017, by the WHO recommendations

\begin{tabular}{|c|c|c|c|c|c|c|c|c|}
\hline Activity & \multicolumn{8}{|c|}{ Domain-specific PA levels } \\
\hline \multicolumn{9}{|l|}{ Overall activity } \\
\hline sufficiently active & 28.2 & $212.2 \pm 43.3$ & 25.7 & $211.0 \pm 43.7$ & 35.7 & $215.7 \pm 45.4$ & 27.4 & $211.3 \pm 43.3$ \\
\hline very active & 61.1 & $706.4 \pm 396.8$ & 68.3 & $800.1 \pm 467.7$ & $50.0^{\mathrm{a}}$ & $548.8 \pm 253.3$ & 57.5 & $631.4 \pm 274.9$ \\
\hline \multicolumn{9}{|c|}{ Work/job-related activity } \\
\hline inactive & 57.9 & $31.1 \pm 40.4$ & 50.5 & $35.8 \pm 43.8$ & $69.0^{\mathrm{a}}$ & $26.6 \pm 42.8$ & $61.6^{\mathrm{b}}$ & $28.7 \pm 34.8$ \\
\hline \multicolumn{9}{|c|}{ Transport-related activity } \\
\hline inactive & 71.8 & $37.9 \pm 17.5$ & 62.4 & $40.2 \pm 18.8$ & $81.0^{\mathrm{a}}$ & $37.4 \pm 19.7$ & $79.5^{\mathrm{b}}$ & $35.8 \pm 14.4$ \\
\hline sufficiently active & 24.5 & $137.8 \pm 46.9$ & 31.7 & $138.9 \pm 52.1$ & $19.0^{\mathrm{a}}$ & $150.0 \pm 45.4$ & $17.8^{\mathrm{b}}$ & $127.7 \pm 33.2$ \\
\hline very active & 3.7 & $495.0 \pm 432.4$ & 5.9 & $550.0 \pm 496.8$ & 0 & 0 & 2.7 & $330.0 \pm 42.4$ \\
\hline \multicolumn{9}{|c|}{ Household/garden chores } \\
\hline inactive & 72.7 & $57.3 \pm 39.4$ & 72.3 & $55.8 \pm 38.1$ & 78.6 & $54.1 \pm 40.7$ & $69.9^{c}$ & $61.6 \pm 40.9$ \\
\hline sufficiently active & 17.6 & $193.3 \pm 29.8$ & 12.9 & $194.6 \pm 28.2$ & $21.4^{\mathrm{a}}$ & $200.0 \pm 26.0$ & 21.9 & $188.4 \pm 33.8$ \\
\hline very active & 9.7 & $492.9 \pm 187.7$ & 14.9 & $500.0 \pm 209.6$ & 0 & 0 & $8.2^{\mathrm{b}}$ & $475.0 \pm 132.0$ \\
\hline
\end{tabular}

a Physiotherapy vs. dietetics.

${ }^{\mathrm{b}}$ Physiotherapy vs. pharmacy.

${ }^{c}$ Dietetics vs. pharmacy.

Significant differences among different points inside the groups $(\mathrm{p}<0.05)$. 


\section{DISCUSSION}

When assessing the PA levels in different populations, particular attention should be paid to medical university students because, as current research shows, the level of PA among those students is still insufficient [19]. The adequate level of PA should be characteristic of those students whose future professional work is to promote healthy lifestyles, to prevent diseases, and to improve the lives of patients with various disabilities [19]. However, a number of studies have shown that HCPs exhibit the same unhealthy behaviors as the general population [20]. Similarly, evidence also demonstrates that personal health behaviors and attitudes of HCPs may influence how they practice clinically, and may also influence how patients view their credibility as health promoters [20].

In the present study, the authors analyzed PA among medical university students of different faculties using the IPAQ classification and the WHO recommendations. To the best of the authors' knowledge, this is the first study comparing PA among medical university students of other faculties than medicine, including the $\mathrm{P}, \mathrm{D}$ and $\mathrm{Ph}$ students.

Notably, IPAQ-LF is a quantifiable way of expressing the level of PA which has been used even by WHO in the World Health Survey [21]. It is also considered a national and international standard for PA surveillance in different countries [22]. Therefore, IPAQ-LF provides excellent opportunities for comparative analyses of PA levels across different populations [23]. It serves the purpose of assessing exercise length, intensity and frequency, which are all very important components of any activity. It further allows one to identify the social groups at risk as well as assess the activity level in referential groups of physically active individuals.

The PA recommendations issued by $\mathrm{WHO}$ were chosen because of their universality and global recognition, which makes it possible to compare data obtained in different populations [22], as is also the case with IPAQ-LF. However, the WHO recommendations are getting stricter than the IPAQ-LF instructions because of the epidemic of different chronic diseases for the development of which the level of PA is also important. It explains why the results regarding the shares of people assigned to given levels of PA, classified according to IPAQ-LF vs. the WHO recommendations, may appear slightly different. However, this did not affect the overall conclusions of the study.

In the present study, nearly $34 \%$ of all the students were classified as sufficiently active and almost $65 \%$ as very active, while only slightly over $1 \%$ were found to be at the lowest level of PA according to the IPAQ scoring protocol [16]. The results of the study conducted among students of Silesian universities, using the same tool, also showed that the overwhelming majority of them were classified at the high or moderate PA level [24]. In contrast, a study conducted in Poland showed that the students who spent most of their time in a sedentary position during the day, i.e., students with a low level of PA, represented only $21 \%$ of all the study participants [15].

Zadarko et al. [25] observed that the level of PA of nursing or midwifery students was significantly lower compared to students of other faculties, and students of Greek universities represented a low level of PA regardless of the type of the university (with science and medical universities involved) [26]. When analyzing PA in every domain separately, it can be seen that students were the most active in the transport domain and the least active in the household domain. Moreover, $56.9 \%$ of all the students still performed an insufficient amount of PA during their leisure time. What is also noticeable in this study is that men were more physically active than women, which is in line with the results obtained in different studies $[15,26]$. Generally, there was no inactive male student. Most of them represented a high level of $\mathrm{PA}$, and they were more active in the work and leisure time domains than women.

Although previous research has shown some gender differences in PA behaviors across all age groups and education levels [10-12], it seemed reasonable to make an analysis by gender in this study group. First, it is worth getting to know during which everyday activities men and women are more likely to undertake PA, which can help in choosing the right forms of intervention to promote PA. In addition, the knowledge transferred during scientific studies may also have a different impact on women and men, which allows assessing the efficiency and universality of education. Future research would be recommended to check to what extent studies in medical fields, especially physiotherapy, can lead to diminishing those differences. This study also investigated whether medical university students meet the WHO recommendations, under which the population aged 18-64 should perform $\geq 150 \mathrm{~min} /$ week of MPA or $\geq 75 \mathrm{~min} /$ week of VPA, or an equivalent combination of these 2 types of PA, supplemented with muscle strength exercises at least twice a week [17].

It was found that over a half of the students met the recommendation of $\geq 75 \mathrm{~min} /$ week of $\mathrm{VPA}$, or 
$\geq 150 \mathrm{~min} /$ week of MPA, during their all-day activity. When analyzing the gender and faculty differences, it was revealed that more males and $\mathrm{P}$ students met the PA recommendations compared to females, and both $\mathrm{D}$ and $\mathrm{Ph}$ students. When analyzing the data in the leisure time domain only, there were still about $64.4 \%$ of the students who did not meet the recommendation of $\geq 75 \mathrm{~min} /$ week of VPA, or $\geq 150 \mathrm{~min} /$ week of MPA. Although it is believed that activity in all 4 domains is more beneficial to human health than activity in only 1 or 2 of them [27], it seems that students can meet the PA recommendations only because of performing heavy physical work.

Some of the students are able to carry out the PA recommendations during transportation, e.g., cycling, or household activities. Unfortunately, there is still a lack of PA performed during leisure time, i.e., this kind of PA which mostly affects the creation of a habit of regular PA throughout one's life [28]. The problem of meeting the PA recommendations is a global concern, and there is even evidence that about one-third of students who had been active on commencing their education at university became inactive or less active during this transition [29].

The main strength of this study is that it was carried out among students of other faculties of health sciences than the medicine students who seem to constitute the most commonly analyzed group of students.

Secondly, the authors applied the long version of IPAQ which allows for a detailed assessment of PA in different domains. In addition, IPAQ is designed in order to standardize measurements of PA in different independent studies, so these results are comparable with other PA studies based on this widely used questionnaire. Moreover, PA was self-reported from 1-week period, which made it possible to define the average daily PA. A shorter duration of the study would make it impossible to capture the day with the most or least intensive activity. Also, the authors analyzed PA performed in various domains during the day, while in most studies, only the PA declared in the leisure time domain is taken into account to determine the level of PA in relation to the WHO recommendations [22]. Due to the fact that PA was presented with reference to both the IPAQ scoring and the WHO recommendations, the data is more comparable with other results which will be referenced to those tools.

However, some marginal notes have to be made. Although IPAQ is a common research tool used to compare PA, and its validity and reliability has been proven many times [30], it is not considered the gold standard indicator and may misclassify some participants [31]. The objectively measured PA, using accelerometers, could give a more precise evaluation of the PA level, but what was the authors' main concern in this study was the cost and feasibility. However, it was noticed that the questionnaire-based PA level assessed by IPAQ-LF correlated positively with PA reported through pedometer registrations [32] and demonstrated satisfactory levels of validity in the study where an accelerometer was used [33]. Self-reporting remains the simplest, most feasible and affordable instrument for PA surveillance [34], but before planning any specific interventions for certain groups at risk of physical inactivity, more precise PA monitoring should be taken into consideration [22]. Also, the selected faculties of studies were quite feminized, so future studies on less homogeneous groups are advocated.

The cohort used in this study could be considered unique, and the participants were expected to be more active as they are constantly exposed to information on the importance of PA in their academic curricula. This is especially true about the $\mathrm{P}$ students who are also trained in planning and motivating their patients to adopt physical exercise regimes. Hence, these findings indicate a clear mismatch between the knowledge and practice in this group of young adults who perform enough PA during leisure time regardless of the faculty. The PA reported by the students is mainly the PA performed during their professional work or transportation. There is still no habit of undertaking regular PA during leisure time. Physical activity during transportation results from the necessity of getting to the classes that take place in various parts of the city. Therefore, there is a threat that, following graduation, this kind of PA will decrease.

In addition, the possible change from physically active work to a more sustained job will also affect PA. The lack of a habit of regular PA during leisure time will cause that future HCPs will lead an inactive lifestyle. Therefore, it seems right to continue to promote PA among students of medical universities, and also to make them aware of how much their attitude to PA can influence their patients in the future. Launching programs which expand the knowledge of the benefits of PA, organizing additional sports classes, or changing the schedule so that students could take various forms of activity seem to be different ways to motivate them to change their lifestyles, and thereby to increase their level of PA. Consequently, students will be better prepared for the role of patient advisers in their future professional work. 


\section{CONCLUSIONS}

The majority of students do not comply with the current PA recommendations for the leisure time domain and have no habit of PA, which may influence their credibility when promoting PA and healthy behaviors as the HCPs of the future.

There is a need to provide an enabling environment for promoting PA among students. In addition, some changes in medical education should be suggested in order to include physical education as a longterm criterion subject in medical school curricula to promote PA among students of different health sciences.

Future research is needed to investigate the exercise barriers that students perceive, which can guide future interventions aimed at improving their PA, and thereby impact on their health and the quality of health care which they will provide.

\section{REFERENCES}

1. Black BIM, Janes J. Physical Therapists' Role in Health Promotion as Perceived by the Patient: Descriptive Survey. Phys Ther. 2016;96(100):1588-96, https://doi.org/10.2522/ ptj.20140383.

2. Mundorf N, Redding CA, Paiva AL. Sustainable Transportation Attitudes and Health Behavior Change: Evaluation of a Brief Stage-Targeted Video Intervention. Int J Environ Res Public Health. 2018;15(1), https://doi.org/10.3390/ ijerph15010150.

3. Anderson C. Health promotion in community pharmacy: the UK situation. Patient Educ Couns. 2000;39(2-3):28591, https://doi.org/10.1016/s0738-3991(99)00025-7.

4. Dąbrowska-Galas M, Plinta R, Dąbrowska J, Skrzypulec-Plinta V. Physical activity in students of the Medical University of Silesia in Poland. Phys Ther. 2013;93(3):38492, https://doi.org/10.2522/ptj.20120065.

5. Atkins JG, Gingras J. Coming and going: Dietetic students' experience of their education. Can J Diet Pract Res. 2009;70(4):181-6, https://doi.org/10.3148/70.4.2009.181.

6. Peleias M, Tempski P, Paro HB, Perotta B, Mayer FB, Enns SC, et al. Leisure time physical activity and quality of life in medical students: results from a multicentre study. BMJ Open Sport Exerc Med. 2017;3(1):e000213, https:// doi.org/10.1136/bmjsem-2016-000213.

7. Frank E, Tong E, Lobelo F, Carrera J, Duperly J. Physical activity levels and counseling practices of U.S. medical students. Med Sci Sports Exerc. 2008;40(3):413-21, https:// doi.org/10.1249/MSS.0b013e31815ff399.
8. Stanford FC, Durkin MW, Stallworth JR, Powell CK, Poston MB, Blair SN. Factors that influence physicians' and medical students' confidence in counseling patients about physical activity. J Prim Prev. 2014;35(3):193-201, https:// doi.org/10.1007/s10935-014-0345-4.

9. Booth JN, Leary SD, Joinson C, Ness AR, Tomporowski PD, Boyle JM, et al. Associations between objectively measured physical activity and academic attainment in adolescents from a UK cohort. Br J Sports Med. 2014;48(3):265-70, https://doi.org/10.1136/bjsports-2013-092334.

10. Ács P, Bergier J, Salonna F, Junger J, Melczer C, Makai A. Gender differences in physical activity among secondary school students in the Visegrad countries (V4). Health Probl Civil. 2016;10:21-9.

11. Holmes ME, Spring KE, Chen C-CJ, Ryuh Y. Differences in Perceived and Measured Physical Activity and Sedentary Indices Among Physical Education Pedagogy Undergraduate Students. In: Proceedings of APHA's 2019 Annual Meeting and Expo; 2019 Nov 2-6.

12. D'Urzo KA, Johnson AM, McEachern BM, McPhee IA, Brennan AM, Fenuta AA, et al. Investigating gender differences in physical activity behaviour and social cognitions towards physical activity among first-year medical students. Med Ed Publish. 2017;49:79, https://doi. org/10.15694/mep.2019.000207.1.

13. Mahony R, Blake C, Matthews J, DonnoghueGO, Cunningham C. Physical activity levels and self-determined motivation among future healthcare professionals: Utility of the Behavioral Regulation in Exercise Questionnaire (BREQ-2). Physiother Theory Pract. 2019; 35:884-90, https://doi.org/10.1080/09593985.2018.145 7112 .

14. Ainsworth BE HW, Herrmann SD, Meckes N, Bassett Jr DR, Tudor-Locke C, Greer JL, et al. The compendium of physical activities: a second update of codes and MET values. Med Sci Sports Exerc. 2011;43(8):1575-81, https://doi. org/10.1249/MSS.0b013e31821ece12.

15. Bergier J, Kapka-Skrzypczak L, Biliński P, Paprzycki P, Wojtyła A. Physical activity of Polish adolescents and young adults according to IPAQ: a population based study. Ann Agric Environ Med. 2012;19(1):109-15.

16. Oyeyemi AL, Oyeyemi AY, Adegoke BO, Oyetoke FO, Aliyu HN, Aliyu SU, et al. The Short International Physical Activity Questionnaire: cross-cultural adaptation, validation and reliability of the Hausa language version in Nigeria. BMC Med Res Methodol. 2011;11:156, https:// doi.org/10.1186/1471-2288-11-156.

17. World Health Organization [Internet]. The Organization; 2020 [cited January 20, 2020]. Global recommendations on physical activity for health. Available from: https:// 
www.who.int/dietphysicalactivity/publications/recommendations18_64yearsold/en.

18. Medina C, Janssen I, Campos I, Barquera S. Physical inactivity prevalence and trends among Mexican adults: results from the National Health and Nutrition Survey (ENSANUT) 2006 and 2012. BMC Public Health. 2013;13:1063, https://doi.org/10.1186/1471-2458-13-1063.

19. Williams AS, Williams CD, Cronk NJ, Kruse RL, Ringdahl EN, Koopman RJ. Understanding the exercise habits of residents and attending physicians: a mixed methodology study. Fam Med. 2015;47(2):118-23.

20. While AE. Promoting healthy behaviours - do we need to practice what we preach? London J Prim Care (Abingdon). 2015;7(6):112-4, https://doi.org/10.1080/17571472. 2015.1113716.

21. Guthold R, Ono T, Strong KL, Chatterji S, Morabia A. Worldwide variability in physical inactivity a 51-country survey. Am J Prev Med. 2008;34(6):486-94, https://doi. org/10.1016/j.amepre.2008.02.013.

22. Tali M, Lusmagi P, Unt E. Leisure time physical activity in Estonian population: adherence to physical activity recommendations and relationships with overweight. Arch Public Health. 2016;74(1):36, https://doi.org/10.1186/ s13690-016-0148-6.

23. Bauman A, Ainsworth BE, Sallis JF, Hagstromer M, Craig CL, Bull FC, et al. The descriptive epidemiology of sitting. A 20-country comparison using the International Physical Activity Questionnaire (IPAQ). Am J Prev Med. 2011;41(2):228-35, https://doi.org/10.1016/j.amepre. 2011.05.003.

24. Młynarski WRM, Czapla K, Garbaciak W. Aerobic Capacity of Students with Different Levelsof Physical Activity as Assessed by IPAQ. J Hum Kinet. 2009;21:89-96.

25. Zadarko EBZ, Nizioł E. Female students' level of physical activity on elected medical faculties against population studies. Przegląd Medyczny Uniwersytetu Rzeszowskiego i Narodowego Instytutu Leków w Warszawie. 2011;2: 188-94.

26. Papathanasiou G, Georgoudis G, Papandreou M, Spyropoulos P, Georgakopoulos D, Kalfakakou V, et al. Reliability measures of the short International Physical Activity
Questionnaire (IPAQ) in Greek young adults. Hellenic J Cardiol. 2009;50(4):283-94.

27. Jurakić D, Pedisić Z, Andrijasević M. Physical activity of Croatian population: cross-sectional study using International Physical Activity Questionnaire. Croat Med J. 2009;50(2):165-73, https://doi.org/10.3325/cmj. 2009.50.165.

28. Itoh H, Kitamura F, Hagi N, Mashiko T, Matsukawa T, Yokoyama K. Leisure-time physical activity in youth as a predictor of adult leisure physical activity among Japanese workers: a cross-sectional study. Environ Health Prev Med. 2017;22(1):37, https://doi.org/10.1186/s12199017-0648-1.

29. Pengpid S, Peltzer K, Kassean HK, Tsala JP, Sychareun V, Müller-Riemenschneider F. Physical inactivity and associated factors among university students in 23 low-, middleand high-income countries. Int J Public Health. 2015;60(5): 539-49, https://doi.org/10.1007/s00038-015-0680-0.

30. Kim Y, Park I, Kang M. Convergent validity of the international physical activity questionnaire (IPAQ): meta-analysis. Public Health Nutr. 2013;16(3):440-52, https://doi. org/10.1017/S1368980012002996.

31. Zwolinsky S, McKenna J, Pringle A, Widdop P, Griffiths C. Physical activity assessment for public health: efficacious use of the single-item measure. Public Health. 2015;129(12): 1630-6, https://doi.org/10.1016/j.puhe.2015.07.015.

32. De Cocker KA, De Bourdeaudhuij IM, Cardon GM. What do pedometer counts represent? A comparison between pedometer data and data from four different questionnaires. Public Health Nutr. 2009;12(1):74-81, https://doi. org/10.1017/s1368980008001973.

33. Boon RM, Hamlin MJ, Steel GD, Ross JJ. Validation of the New Zealand Physical Activity Questionnaire (NZPAQ-LF) and the International Physical Activity Questionnaire (IPAQ-LF) with accelerometry. Br J Sports Med. 2010;44(10): 741-6, https://doi.org/10.1136/bjsm.2008.052167.

34. Ranasinghe C, Sigera C, Ranasinghe P, Jayawardena R, Ranasinghe ACR, Hills AP, et al. Physical inactivity among physiotherapy undergraduates: exploring the knowledge-practice gap. 2016. BMC Sports Sci Med Rehabil. 2016;8:39, https://doi.org/10.1186/s13102-016-0063-8

This work is available in Open Access model and licensed under a Creative Commons Attribution-NonCommercial 3.0 Poland License - http://creativecommons.org/licenses/by-nc/3.0/pl/deed.en. 